\title{
Assessment of Sirolimus-Eluting Coronary Stent Implantation With Aspirin Plus Low Dose Ticlopidine Administration One Year Results From CYPHER Stent Japan Post-Marketing Surveillance Registry (J-PMS)
}

\author{
Yuji Ikari, MD; Junichi Kotani, MD*; Ken Kozuma, MD**; Eishou Kyo, MD ${ }^{\dagger}$; \\ Masato Nakamura, MD ${ }^{\dagger+}$; Hiroyoshi Yokoi, MD \\ on behalf of the J-PMS study group
}

\begin{abstract}
Background: Clinical data of sirolimus-eluting stent (SES) implantation are under investigation in Japan. Methods and Results: The CYPHER stent Japan Post-Marketing Surveillance Registry (J-PMS) was conducted at 50 medical centers to assess the results of SES in daily clinical practice exclusively under aspirin plus low dose ticlopidine $(200 \mathrm{mg} /$ day $)$. A total of 2,459 lesions in 2,054 patients were treated with 3,285 SES. The mean age was $67.1 \pm 10.1$ years, $75.6 \%$ were men and $43.3 \%$ were diabetics. Intravascular ultrasound was used in $77.2 \%$. The 8-month angiographic and 1-year clinical follow-up data were available in $85.4 \%$ and $96.8 \%$, respectively. Quantitative coronary angiography showed the reference vessel diameter and percentage diameter stenosis at baseline were $2.47 \pm 0.58 \mathrm{~mm}$ and $72.0 \pm 16.1 \%$. The 8 -month late loss was $0.20 \pm 0.50 \mathrm{~mm}$. The major adverse cardiovascular events at 1 year was $7.3 \%$; cardiac death: $1.1 \%$, myocardial infarction (MI): $1.2 \%$, and target lesion revascularization (TLR): $4.2 \%$. The rates of definite and probable stent thrombosis at 1 year were $0.30 \%$ and $0.10 \%$, respectively. Hemodialysis was the strongest predictor of death/MI or TLR.

Conclusions: J-PMS showed the effectiveness of SES implantation under aspirin plus low dose ticlopidine administration at 1 year, although further studies are necessary to demonstrate the safety. (Circ J 2009; 73: $1038-1044)$
\end{abstract}

Key Words: Antiplatelet therapy; Coronary disease; Drug-eluting stents; Thrombosis

A lot of clinical results of sirolimus-eluting stent (SES) (CYPHER stent; Johnson \& Johnson-Cordis Corp, Warren, NJ, USA) have been reported in many randomized control trials and registries under thienopyridine therapy in combination with aspirin!-9 Ticlopidine was commonly used for bare metal stent implantation, but clopidogrel has been considered a favorable thienopyridine for drug-eluting stent (DES) implantation!0-14 Thus, most patients enrolled in the above studies had taken clopidogrel. Although dual antiplatelet therapy has become the mainstay to reduce the risk of stent thrombosis, several factors contribute to premature cessation of thienopyridine, including economic reasons ${ }^{15}$ Therefore, use of ticlopidine might improve compliance as a result of its lower cost. However, effectiveness with aspirin plus ticlopidine for SES implantation has not been established because sufficiently large data set is not available.

Since clopidogrel had not been approved to use for

(Received September 4, 2008; revised manuscript received January 7 , 2009; accepted January 12, 2009; released online April 14, 2009)

Tokai University School of Medicine, Isehara, *Osaka University School of Medicine, Suita, **Teikyo University School of Medicine, Tokyo, 'Shiga Heart Center, Kusatsu, †Toho University School of Medicine, Tokyo and $¥$ Kokura Memorial Hospital, Kokura, Japan

Mailing address: Yuji Ikari, MD, Department of Cardiology, Tokai University School of Medicine, 143 Shimokasuya, Isehara 259-1193, Japan. E-mail: ikari@is.icc.u-tokai.ac.jp

All rights are reserved to the Japanese Circulation Society. For permissions, please e-mail: cj@j-circ.or.jp percutaneous coronary intervention (PCI) in Japan until recently, we had to use ticlopidine for SES implantation. In addition, the approved dose of ticlopidine was $200 \mathrm{mg} / \mathrm{day}$ not $500 \mathrm{mg} /$ day. We herein report the real world registry data of SES including off-label and complex cases under aspirin plus low dose ticlopidine $(200 \mathrm{mg} /$ day $)$ administration.

\section{Methods}

\section{Study Design and Patient Enrollment}

CYPHER stent Japan Post-Marketing Surveillance Registry (J-PMS) is a post-marketing surveillance registry that was mandated by the Japanese government to fulfill one of the regulatory approval conditions. The primary objective is to assess the results of SES in daily clinical practice under aspirin plus ticlopidine. The secondary objective is to evaluate the efficacy of SES in Japanese patients with angiographic evaluation of late loss and binary restenosis, thus angiographic follow-up at 8 months was mandated. A total of 2,000 cases implanted with SES were planned to enroll consecutively from September 2004 through September 2005 at 50 community-based and university hospitals that are representative of clinical environment nationwide in Japan. Total enrollment at each site was targeted to be 20 80 patients in proportion to the annual scale of PCI procedures. The indications for stent implantation were left to the discretion of each cardiologist participating in the registry, including off-label use. 
Table 1. Baseline Clinical Characteristics

\begin{tabular}{|c|c|}
\hline No. of patient & 2,051 \\
\hline Age, years & $67.1 \pm 10.1$ \\
\hline Male sex & $1,550(75.6)$ \\
\hline \multicolumn{2}{|l|}{ Angina pectoris } \\
\hline Unstable angina & $277(13.5)$ \\
\hline Stable angina & $1,096(53.4)$ \\
\hline CCS Classification III or IV & $115(5.6)$ \\
\hline MI & $411(20.0)$ \\
\hline Acute MI $(\leq 72 \mathrm{~h})$ & $88(4.3)$ \\
\hline Recent MI & $54(2.6)$ \\
\hline Old MI & $269(13.1)$ \\
\hline Silent ischemia & $255(12.4)$ \\
\hline Others & $12(0.6)$ \\
\hline Elective cases & $1,883(91.8)$ \\
\hline Ejection fraction $<50 \% *$ & $435(25.1)$ \\
\hline Previous MI & 778 (37.9) \\
\hline Previous coronary angioplasty & $1,153(56.2)$ \\
\hline Previous CABG surgery & $166(8.1)$ \\
\hline Hyperlipidemia & $1,164(56.8)$ \\
\hline Hypertension & $1,429(69.7)$ \\
\hline Diabetes & $889(43.3)$ \\
\hline Insulin treatment & $207(10.1)$ \\
\hline Current smoker & $905(44.1)$ \\
\hline Dialysis & $105(5.1)$ \\
\hline Cerebrovascular disease & $160(7.8)$ \\
\hline Peripheral vascular disease & $130(6.3)$ \\
\hline \multicolumn{2}{|l|}{ No. of diseaesed vessel } \\
\hline 1-vessel disease & $1,206(58.8)$ \\
\hline 2-vessel disease & $563(27.5)$ \\
\hline 3-vessel disease & $282(13.7)$ \\
\hline Use of glycoprotein IIb/IIIa inhibitor & $0(0.0)$ \\
\hline Use of ticlopidine & $2,020(98.5)$ \\
\hline
\end{tabular}

Value are mean $\pm \mathrm{SD}$ or $\mathrm{n}(\%)$.

CCS, Canadian Cardiovascular Society; MI, myocardial infarction; CABG, coronary artery bypass graft.

$*$ Denominator $=1,733$.

\section{Antiplatelet Therapy}

To reduce risk of stent thrombosis, it was recommended that aspirin (81-200 mg daily) should be administered preprocedure and continued indefinitely, and ticlopidine (200 mg daily) should be administered concomitantly with aspirin and for a period of 3 months post-procedure in Japan. However, the management of antiplatelet therapy; initiation and discontinuation, including unavoidable ticlopidine discontinuation due to side effects or surgical operation, was left to the discretion of each cardiologist at participating study sites.

\section{Data Collection and Management}

The post-marketing surveillance databases were developed by Johnson \& Johnson K.K. in Japan. Detailed demographics, clinical, angiographic and procedural information including complications were gathered for each patient. The data have been entered into case report forms by participating sites and collected by Johnson \& Johnson K.K. Follow-up data were collected at 3, 8, 12 months and will be collected yearly up to 5 years. Angiographic data on 1,063 of 2,459 lesions were analyzed by an independent core laboratory (Cardiocore, Tokyo, Japan) and the remaining angiograms were analyzed by on-site quantitative coronary angiography (QCA). An independent safety and efficacy evaluation committee adjudicated all reported and suspected major adverse cardiovascular events (MACE) defined as death, myocardial infarction (MI) and target lesion revascularization (TLR) by PCI or by coronary artery bypass
Table 2. Lesion Characteristics

\begin{tabular}{lc}
\hline No. of lesions & 2,459 \\
Target coronary artery & \\
Right coronary artery & $751(30.5)$ \\
Left anterior descending artery & $1,075(43.7)$ \\
Left circumflex artery & $522(21.2)$ \\
Left main coronary artery & $95(3.9)$ \\
HL & $16(0.7)$ \\
ACC/AHA Classification* & \\
Type B2/C & $1,981(80.9)$ \\
Lesion characteristecs & \\
De novo & $1,946(79.1)$ \\
In-stent restenosis & $363(14.8)$ \\
Moderate/severe calcification & $426(17.3)$ \\
Ostial lesion & $511(20.8)$ \\
Right coronary artery ostial lesion & $110(4.5)$ \\
Left coronary artery ostial lesion & $69(2.8)$ \\
Total occulusion & $276(11.2)$ \\
CTO (less than 3 months) & $101(4.1)$ \\
CTO (more than 3 months) & $111(4.5)$ \\
Unknown & $64(2.6)$ \\
No. of lesions & 2,459 \\
No. of stents & 3,285 \\
Direct stenting & $538(21.9)$ \\
Intravascular ultrasound using & $1,776(77.2)$ \\
Maximum deployment pressure & $16.0 \pm 3.5$ \\
Stents/patient ratio & $1.6 \pm 0.9$ \\
Stents/lesion ratio & $1.3 \pm 0.6$ \\
Post dilatation & $1,142(46.4)$ \\
Post dilatation maximum pressure & $17.4 \pm 4.5$ \\
\hline
\end{tabular}

Value are mean $\pm \mathrm{SD}$ or $\mathrm{n}(\%)$.

$\mathrm{HL}$, high lateral branch; ACC/AHA, American College of Cardiology/ American Heart Association; CTO, chronic total occlusion.

*Denominator $=2,449$.

graft surgery (CABG); stent thromboses; and target vessel revascularization (TVR) by PCI or CABG. The adjudications were based on the information contained in the case report form and on the responses to queries addressed to the participating study sites.

Deaths were classified as cardiac or non-cardiac based on SIRIUS trial protocol definition, so unidentified death, that was any death in which a cardiac cause could not be excluded was classified as cardiac in this study. MI were classified as Q wave and non-Q wave by the physicians' discretions on the basis of ECG changes and/or a rise in creatine kinase enzyme concentration above twice the upper normal limit. If no information to judge classification of MI was available, it was classified as unidentified. TLR were based on the SIRIUS trial protocol definition and, all reported re-interventions inside the implanted stent or within $5 \mathrm{~mm}$ proximal or distal to the stent were classified as TLR. Repeated PCI in the same vessel was recorded as non-target lesion TVR (non-TL TVR). Stent thrombosis was classified based on Academic Research Consortium (ARC) definition as 'definite' or 'probable', and 'early' (0-30 days after implantation) or 'late' (31-360 days after implantation).

\section{Statistical Analysis}

Data were expressed as mean \pm SD for continuous variables and as frequencies for the categorical variables. Categorical variables that were significant on univariate analysis to determine their independent relation to TLR, were analyzed by the Fisher's exact test. Statistical significance was declared if the 2 -sided probability value was $<0.05$. Eventfree (death free, death + MI free, MACE free) and administration of ticlopidine during the 12 months follow-up period 
Table 3. Major Adverse Cardiac Events

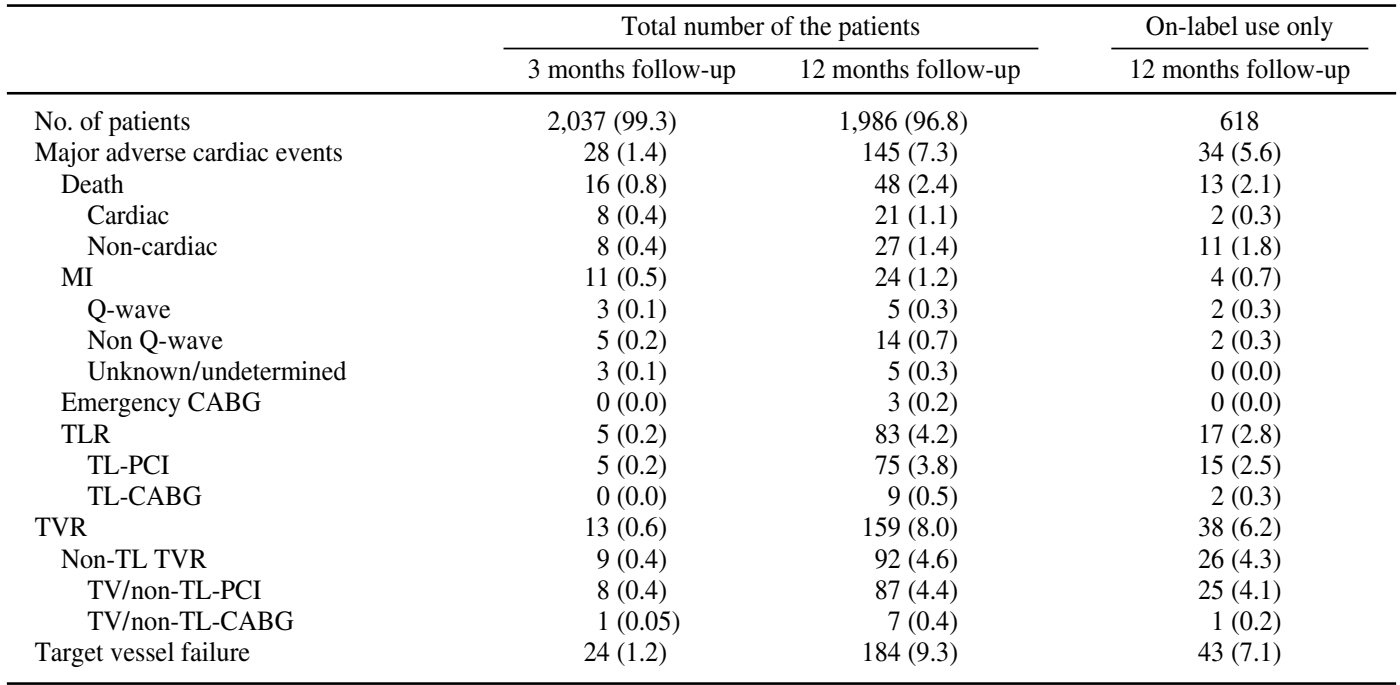

Values are $\mathrm{n}(\%)$.

TLR, target lesion revascularization; TL, target lesion; PCI, percutaneous coronary intervention; TVR, target vessel revascularization.

Other abbreviation see in Table 1 .
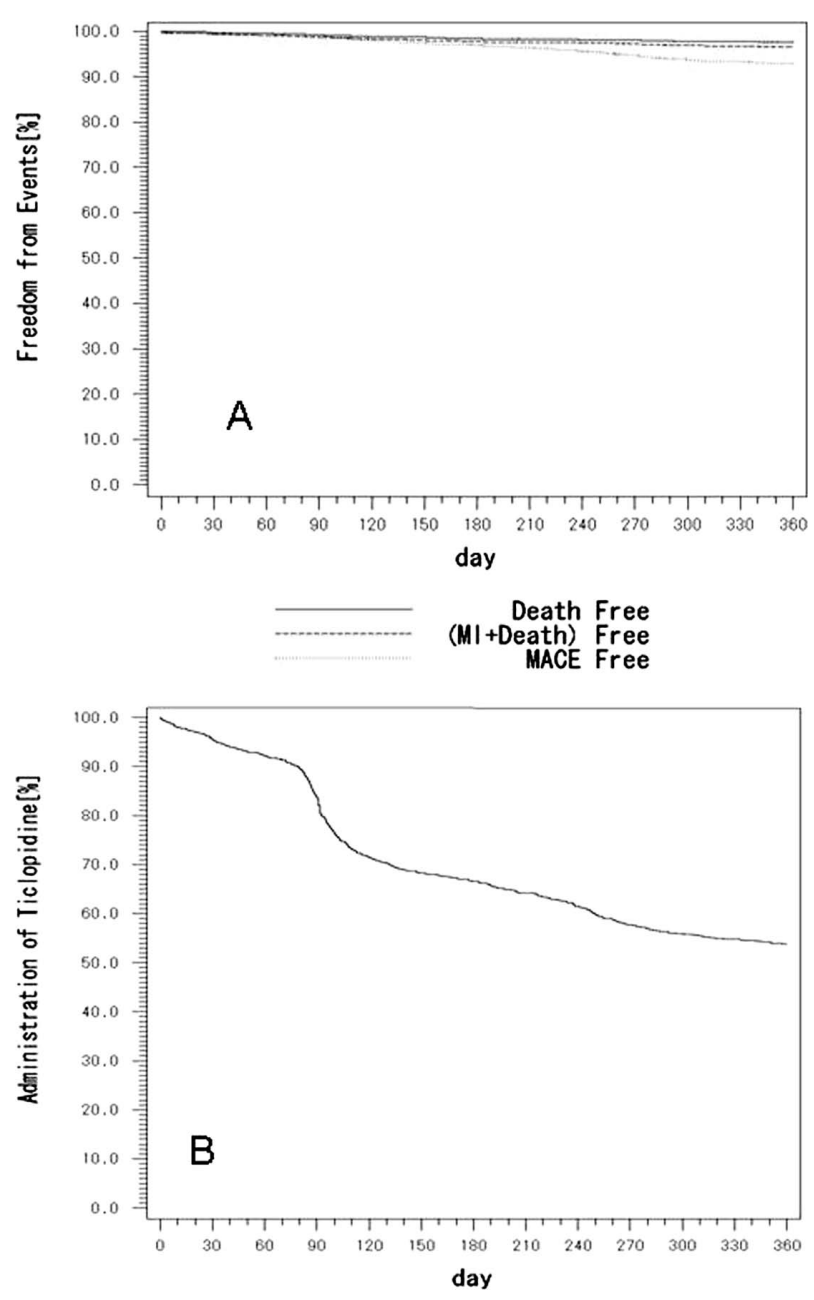

Figure. (A) Kaplan-Meier event free curve. MI, myocardial infarction; MACE, major adverse cardiac events including death, MI and target lesion revascularization. (B) Administration of ticlopidine. were analyzed by the Kaplan-Meier method. Statistical analysis was performed with SAS ver 8.2 (SAS Institute, Cary, NC, USA).

\section{Results}

\section{Patients and Follow-up Compliance}

A total of 2,054 cases/2,464 lesions were enrolled. The mean age was $67.1 \pm 10.1,75.6 \%$ were men, and $43.3 \%$ were diabetics including $10.1 \%$ with insulin treatment. Glycoprotein IIbIIIa inhibitors were not used because they were unavailable in Japan. The baseline characteristics are detailed in Table 1. Note that this study included 1,401 cases $(68.3 \%)$ that could be considered high risk, so called 'offlabel use'. This included acute MI treatment, unprotected left main coronary artery, bifurcation, ostial, restenotic lesion, non-native vessel, chronic total occlusion or long lesions over $30 \mathrm{~mm}$.

\section{Lesion Characteristics}

A total of 3,279 SES were implanted into 2,458 lesions during the index procedure. Delivery failure of SES was observed in 5 lesions, and thus the initial success rate of implantation of SES was $99.8 \%(2,453 / 2,458$ lesions $)$. The stent lengths were 13 to $33 \mathrm{~mm}$ and diameters between 2.5 and $3.5 \mathrm{~mm}$. Lesion characteristics are shown in Table 2. It is noteworthy that the average of maximum deployment pressure of SES was high, post-dilatation was performed with another balloon in $46.4 \%$, intravascular ultrasound (IVUS) was used in $77.2 \%$ of the procedure.

\section{Clinical Follow-up}

Follow-up data were available for 2,037 patients at 3 months, and 1,986 patients at 1 year, representing $99.3 \%$ and $96.8 \%$ compliance, respectively. Follow-up data are listed in Table 3. Event free survival curves are shown in Figure.

\section{Angiographic Follow-up}

Angiographic follow-up data at 8 months were available 
Table 4. Results of Quantitative Coronary Analysis at Baseline and at 8 Months Follow-up (Core Lab)

\begin{tabular}{|c|c|c|c|c|}
\hline & In-lesion (n) & Proximal-margin (n) & In-stent (n) & Distal-margin (n) \\
\hline Lesion length, mm & $16.40 \pm 9.89(904)$ & - & - & - \\
\hline \multicolumn{5}{|c|}{ Reference diameter, $\mathrm{mm}$} \\
\hline Before procedure & $2.47 \pm 0.58(950)$ & - & - & - \\
\hline After procedure & $2.50 \pm 0.51(951)$ & $2.92 \pm 0.50(740)$ & $2.63 \pm 0.49(951)$ & $2.45 \pm 0.48(942)$ \\
\hline At 8 months & $2.60 \pm 0.49(949)$ & $2.93 \pm 0.52(743)$ & $2.67 \pm 0.49(948)$ & $2.50 \pm 0.47(937)$ \\
\hline \multicolumn{5}{|l|}{ MLD, mm } \\
\hline Before procedure & $0.70 \pm 0.45(952)$ & - & - & - \\
\hline After procedure & $1.83 \pm 0.51(951)$ & $2.37 \pm 0.58(740)$ & $2.29 \pm 0.43(951)$ & $1.88 \pm 0.54(942)$ \\
\hline At 8 months & $1.79 \pm 0.58(952)$ & $2.35 \pm 0.62(745)$ & $2.09 \pm 0.60(952)$ & $1.98 \pm 0.56(939)$ \\
\hline \multicolumn{5}{|l|}{$\% \mathrm{DS}$} \\
\hline Before procedure & $72.0 \pm 16.1(952)$ & - & - & - \\
\hline After procedure & $26.8 \pm 13.4(951)$ & $19.0 \pm 12.8(740)$ & $12.6 \pm 9.3(951)$ & $23.7 \pm 14.1(942)$ \\
\hline At 8 months & $30.9 \pm 18.5(952)$ & $19.8 \pm 15.4(745)$ & $21.5 \pm 18.8(952)$ & $21.1 \pm 14.6(939)$ \\
\hline Acute gain, mm & $1.13 \pm 0.53(951)$ & - & $1.59 \pm 0.50(951)$ & - \\
\hline Late loss, mm & $0.04 \pm 0.49(951)$ & - & $0.20 \pm 0.50(951)$ & - \\
\hline Late loss index, mm & $0.08 \pm 2.48$ & - & $0.13 \pm 0.49(951)$ & - \\
\hline Binary restenosis & $13.1 \%(125 / 952)$ & $4.8 \%(36 / 745)$ & $8.0 \%(76 / 952)$ & $2.8 \%(26 / 939)$ \\
\hline
\end{tabular}

Value are mean \pm SD or $\%$. This table shows only the core lab analysis data.

MLD, minimum lumen diameter; \%DS, percent diameter stenosis.

Table 5. Sub-Analysis of Predictors for Death Plus MI or TLR

\begin{tabular}{|c|c|c|c|c|}
\hline Predictor & Yes & No & $P$ value & $\mathrm{OR}(95 \% \mathrm{CI})$ \\
\hline \multicolumn{5}{|l|}{ Death +MI } \\
\hline Dialysis & $12.9 \%(13 / 101)$ & $3.0 \%(56 / 1,885)$ & $<0.001$ & $4.825(2.544-9.152)$ \\
\hline Previous MI & $5.4 \%(41 / 759)$ & $2.3 \%(28 / 1,227)$ & $<0.001$ & $2.445(1.499-3.989)$ \\
\hline Hyperlipidemia & $2.3 \%(26 / 1,128)$ & $5.0 \%(43 / 858)$ & 0.001 & $0.447(0.273-0.734)$ \\
\hline Cerebrovascular disease & $7.6 \%(12 / 157)$ & $3.1 \%(57 / 1,829)$ & 0.004 & $2.573(1.350-4.904)$ \\
\hline Age $>74$ years old & $5.3 \%(26 / 489)$ & $2.9 \%(43 / 1,497)$ & 0.012 & $1.899(1.154-3.124)$ \\
\hline Previous PCI & $3.8 \%(43 / 1,123)$ & $3.0 \%(26 / 863)$ & 0.326 & $1.282(0.781-2.103)$ \\
\hline Diabetes & $3.0 \%(26 / 860)$ & $3.8 \%(43 / 1,126)$ & 0.339 & $0.785(0.479-1.288)$ \\
\hline Current smoking & $4.0 \%(15 / 377)$ & $3.4 \%(54 / 1,609)$ & 0.553 & $1.193(0.666-2.138)$ \\
\hline Hypertension & $3.4 \%(47 / 1,389)$ & $3.7 \%(22 / 597)$ & 0.737 & $0.915(0.547-1.533)$ \\
\hline Peripheral vascular disease & $4.0 \%(5 / 126)$ & $3.4 \%(64 / 1,860)$ & 0.755 & $1.160(0.458-2.935)$ \\
\hline Multivessel disease & $3.5 \%(29 / 817)$ & $3.4 \%(40 / 1,169)$ & 0.878 & $1.039(0.639-1.690)$ \\
\hline Previous CABG & $3.7 \%(6 / 163)$ & $3.5 \%(63 / 1,823)$ & 0.880 & $1.068(0.455-2.506)$ \\
\hline Female & $3.5 \%(17 / 487)$ & $3.5 \%(52 / 1,499)$ & 0.982 & $1.007(0.576-1.757)$ \\
\hline \multicolumn{5}{|l|}{ TLR rate } \\
\hline Dialysis & $15.8 \%(16 / 101)$ & $3.6 \%(67 / 1,885)$ & $<0.001$ & $5.881(3.410-10.140)$ \\
\hline Mod./severe calcification & $6.7 \%(27 / 406)$ & $3.1 \%(62 / 1,972)$ & 0.001 & $2.195(1.378-3.495)$ \\
\hline Lesion length $>30 \mathrm{~mm}$ & $7.0 \%(18 / 258)$ & $3.1 \%(62 / 1,973)$ & 0.004 & $2.313(1.346-3.975)$ \\
\hline $\mathrm{RVD}<2.5 \mathrm{~mm}$ & $4.8 \%(53 / 1,101)$ & $2.6 \%(31 / 1,181)$ & 0.007 & $1.876(1.195-2.945)$ \\
\hline Diabetes & $5.6 \%(48 / 860)$ & $3.1 \%(35 / 1,126)$ & 0.009 & $1.985(1.287-3.062)$ \\
\hline Ostial & $5.7 \%(23 / 401)$ & $3.3 \%(66 / 1,977)$ & 0.029 & $1.762(1.082-2.868)$ \\
\hline Multivessel disease & $5.4 \%(44 / 817)$ & $3.3 \%(39 / 1,169)$ & 0.030 & $1.256(0.822-1.918)$ \\
\hline Restenosis & $5.4 \%(27 / 498)$ & $3.3 \%(62 / 1,880)$ & 0.033 & $1.681(1.058-2.671)$ \\
\hline Previous PCI & $5.0 \%(56 / 1,123)$ & $3.1 \%(27 / 863)$ & 0.042 & $1.482(0.951-2.310)$ \\
\hline Bifurcation & $4.6 \%(36 / 784)$ & $3.3 \%(53 / 1,594)$ & 0.135 & $1.254(0.673-2.337)$ \\
\hline ACC/AHA B2/C & $4.0 \%(77 / 1,919)$ & $2.7 \%(12 / 449)$ & 0.215 & $1.400(0.908-2.156)$ \\
\hline Total occlusion & $4.5 \%(12 / 265)$ & $3.6 \%(77 / 2,113)$ & 0.490 & $1.522(0.821-2.822)$ \\
\hline Previous MI & $4.0 \%(30 / 759)$ & $4.3 \%(53 / 1,227)$ & 0.730 & $0.845(0.542-1.317)$ \\
\hline
\end{tabular}

OR, odds ratio; CI, confidence interval; RVD, reference vessel diameter. Other abbreviations see in Tables 1-3.

in 1,752 patients $(85.4 \%)$, which included 812 patients enrolled for core laboratory analysis (Table 4). The insegment binary restenosis rate was 9.0\% (187/2,087 lesions) in overall QCA data. The core-lab QCA data showed the instent binary restenosis rate and late loss were 8.0\% (76/952 lesions) and $0.20 \pm 0.50 \mathrm{~mm}$.

\section{Predictors of TLR}

Predictors of TLR are shown in Table 5. Significant predictors of TLR were multiple vessel disease, diabetes, dialysis, restenotic lesions, small reference vessel, long lesion and calcified lesions. The result of univariate analy- sis indicated dialysis was the most significant predictor of TLR in this study.

\section{Antiplatelet Drugs and Stent Thrombosis}

Aspirin was administrated continuously to 1 year after stent implantation. Meanwhile the use of ticlopidine decreases significantly approximately 3 months partly as shown in Figure B because the recommendation of administration period for ticlopidine was at least 3 months after implantation in the SES instruction for use in Japan. The reasons for discontinuation of ticlopidine were as follows: $42.3 \%$ secondary to ticlopidine side effects, $38.9 \%$ judg- 
Table 6. Stent Thrombosis Rate Based on Academic Research Consortium Definition

\begin{tabular}{lccc}
\hline Stent thrombosis & $\begin{array}{c}\text { Early } \\
(0-30 \text { days })\end{array}$ & $\begin{array}{c}\text { Late } \\
(31-360 \text { days })\end{array}$ & Total \\
\hline No. of patients & 2,037 & 1,986 & 1,986 \\
Definite & $1(0.05)$ & $5(0.25)$ & $6(0.30)$ \\
Probable & $0^{*}(0.00)$ & $2(0.10)$ & $2(0.10)$ \\
Possible & $0(0.00)$ & $14(0.70)$ & $14(0.70)$ \\
Definite +probable & $1(0.05)$ & $7(0.35)$ & $8(0.40)$ \\
Total & $1(0.05)$ & $21(1.06)$ & $22(1.11)$ \\
\hline
\end{tabular}

Values are $\mathrm{n}(\%)$.

*Exclude one case with procedure failure (MI occurred during PCI procedure).

Abbreviations see in Tables 1,3.

ment of full-term, $4.7 \%$ from complications other than ticlopidine side effects, $3.4 \%$ non-compliance or errors in description, $2.7 \%$ due to surgical operations, and $8.1 \%$ for unknown reasons. Detailed data of ticlopidine side effects were as follows: $24.2 \%$ hepatic disorder, $10.1 \%$ skin rash, $7.3 \%$ any abnormal biochemical test, $0.3 \%$ deterioration of renal function and $0.3 \%$ agranulocytosis. No thrombotic thrombocytopenic purpura was reported in this study.

In this situation, the rates of 'definite' and 'definite or probable' thrombosis within 1 year were $0.30 \%$ and $0.40 \%$, respectively (Table 6). In the total of 8 patients, 2 patients took dual antiplatelet drugs, 1 took only aspirin, and the remaining patients discontinued dual APT (unknown, 3, 6, 55 and 149 days before thrombosis occurred, respectively).

\section{Discussion}

The J-PMS is a unique study because the initial dual antiplatelet regimen was aspirin plus low dose ticlopidine for all patients without exception. Clopidogrel had not been approved for use in Japan during the conduct of this study. There were no data to confirm the efficacy of ticlopidine as an antiplatelet drug for DES implantation. Additionally, there was a concern about the risk of severe ticlopidine side effects. Thus, the J-PMS was mandated by the government.

Pharmacologic studies show there is a linear increase in antiplatelet effects an increasing dose of ticlopidine. The $90 \%$ of maximal effect is seen approximately 200 to $250 \mathrm{mg}$ and it is almost a plateau with only a small increase up to $500 \mathrm{mg}$. $^{1-18}$ Thus, the usual dose selection was $500 \mathrm{mg}$, which was almost doubling the dose for reaching plateau. In China, $250 \mathrm{mg} /$ day ticlopidine therapy was suggested to prevent side effects. ${ }^{9}$ In Japan, ticlopidine was approved at the dose of $300 \mathrm{mg} /$ day in the $1980 \mathrm{~s}$ but the Japanese physicians reduced the dose to $200 \mathrm{mg}$ /day due to frequent side effects of hepatic disorder. This dose has been used in daily practice for more than 1 decade.

Only limited amounts of data were available comparing ticlopidine $200 \mathrm{mg}$ and clopidogrel $75 \mathrm{mg}$. There is a doubleblind randomized study comparing ticlopidine $200 \mathrm{mg}$ and clopidogrel $75 \mathrm{mg}{ }^{20}$ The study did no show any significant difference in the prevention of strokes between the 2 groups; however, the frequency of side effects almost doubled in the ticlopidine group as in the clopidogrel group. The REACH registry in Japan arm showed the event rate using ticlopidine $200 \mathrm{mg} /$ day was similar to other countries. ${ }^{21}$ These observations suggest that the antiplatelet effect of ticlopidine $200 \mathrm{mg} /$ day was sufficient to prevent thrombotic events in Japan with lower side effect rate of ticlopidine?2,23
A benefit of this study is the limited case selection bias because no other DESs were available during the study period in Japan. On the contrary, there were several Japanspecific risk factors such as small reference vessel diameter (the average was $2.47 \mathrm{~mm}$ ), high percent of diabetics $(43.3 \%)$ and off-label use $(68.3 \%)$, including $11.2 \%$ total occlusion. Despite treating high risk lesions with low dose ticlopidine, J-PMS data showed event rates are equal to or lower than other studies in other countries. ${ }^{2-5,7,8,24-33}$ The rates at 1 year of definite and probable stent thrombosis, MACE and target vessel failure: $0.40 \%, 7.3 \%$ and $9.3 \%$ are acceptable because other registry studies showed these results ranged from $0.4 \%^{3}$ to $1.3 \% ;^{22} 5.8 \% 7$ to $15 \% ;^{23}$ and $9.8 \%{ }^{3}$ to $12 \%{ }^{21}$ respectively ? $^{2,7,7,8,24-32}$ Before the launch of the CYPHER stent in Japan, educational instruction courses were conducted all over the country to teach high maximal inflation pressure ${ }^{34-37}$ and confirmation of stent full expansion with IVUS, if possible ${ }^{38-41} \mathrm{~J}-\mathrm{PMS}$ showed high rate of IVUS usage (77.2\%) and high inflation pressure (16.0土 $3.5 \mathrm{~atm})$. These courses could have helped to achieve the current favorable results, even with the high percentage of off-label use. ${ }^{2}$

Predictors of hard endpoints (death plus MI) and TLR were shown in Table 5. We found that dialysis was the strongest predictor of not only TLR but also death plus MI. This study included $5.1 \%$ dialysis patients which was a higher rate compared to other studies. Results of DESs for dialysis patients have not been clarified but data from this study might suggest we need to focus on the data of dialysis patients. ${ }^{3}$

Limitations of this study are as follows: these were interim results of J-PMS study with 1 year follow-up rate $96.8 \%$. The study is mandated up to 5-year follow-up, so the data will be updated and finalized by completing follow-up with all patients. Platelet reaction to drugs might be different in other races and the data should be confirmed in other countries. QCA was performed in only half of the patients at the independent core laboratory. In conclusion, this study showed acceptable results with SES with aspirin plus low dose of ticlopidine $(200 \mathrm{mg} /$ day $)$ compared to other registry studies with aspirin plus clopidogrel-5,7,8,24-33 although approximately half of the patients quitted ticlopidine within 1 year mainly due to side effects. Low dose of ticlopidine administration might be a cost-effective substitute of clopidogrel after SES implantation in Japanese populations.

\section{Acknowledgments}

The following investigators and institutions participated in CYPHER stent Japan Post-Marketing Surveillance: Safety and Efficacy Evaluation Committee Board-Y. Ikari, Tokai University School of Medicine; M. Nakamura, Toho University Ohashi Medical Center; H. Yokoi, Kokura Memorial Hospital; E. Kyo, Kusatsu Heart Center; J. Kotani, Osaka University Hospital. Clinical Site-Y. Hamazaki, Showa University Hospital; T. Tamura, Itabashi Chuo Medical Center; Y. Hiasa, Tokushima Red Cross Hospital; T. Shibata, Miyazaki Medical Association Hospital; K. Hirata, Okinawa Chubu Hospital; Y. Nagai, Rinku General Medical Center; M. Tanaka, Osaka Red Cross Hospital; S. Nakamura, Kyoto-Katsura Hospital; R. Hamada, Hokuto Cardiovascular Hospital; Y. Katsuta, Fukuoka City Medical Association Hospital; T. Isshiki, Teikyo University Hospital; T. Hirabayashi, Sunagawa City Medical Center; M. Iwabuchi, Kokura Memorial Hospital; K. Hara, Mitsui Memorial Hospital; R. Asano, Sakakibara Heart Institute; S. Saito, Shonan Kamakura General Hospital; H. Nonogi, National Cardiovascular Center; T. Kimura, Kyoto University Hospital; H. Kanno, Katta Hospital; K. Inoue, South Miyagi Medical Center; M. Nakamura, Toho University Ohashi Medical Center; Y. Ota, Saiseikai Kurihashi Hospital; N. Komatsu, Ohta General Hospital Foundation, Ohta Nishinouchi Hospital; M. Kijima, Hoshi General Hospital; J. Hirose, Comfort Hospital; Y. Fujimoto, Kimitsu Central Hospital; K. Tamaki, 
Iwate Prefectural Central Hospital; Y. Hayashi, Tsuchiya General Hospital; T. Oie, National Hospital Organization Oita Medical Center; H. Ogawa, Tokuyama Central Hospital; K. Mitsudo, Kurashiki Central Hospital; K. Ueda, Otowa Hospital; K. Kosuga, Shiga Medical Center for Adults; S. Ishiwata, Toranomon Hospital; H. Fujita, Kyoto Second Red Cross Hospital; K. Fukui, Kanagawa Cardiovascular and Respiratory Center; H. Oda, Niigata City General Hospital; Y. Noguchi, Tsukuba Medical Center Hospital; I. Michishita, Yokohama Sakae Kyosai Hospital; S. Nanto, Kansai Rosai Hospital; H. Hirayama, Nagoya Daini Red Cross Hospital; M. Watarai, Anjo Kosei Hospital; H. Takashima, Aichi Medical University; A. Takizawa, Shizuoka City Shizuoka Hospital; N. Tanaka, Toyohashi Heart Center; M. Kashida, International Medical Center of Japan; T. Hayashi, Himeji Cardiovascular Center; T. Ota, Matsue City Hospital; T. Kataoka, Osaka City University Hospital; I. Kubo, Metropolitan Bokutou Hospital; Y. Ikari, Tokai University, School of Medicine.

\section{Funding Sources}

Funding was provided from Johnson \& Johnson Cordis Corp (Warren, NJ, USA).

\section{Disclosures}

All authors reported no conflict of interests.

\section{References}

1. Morice MC, Serruys PW, Sousa JE, Fajadet J, Ban Hayashi E, Perin $\mathrm{M}$, et al. A randomized comparison of a sirolimus-eluting stent with a standard stent for coronary revascularization. N Engl J Med 2002; 346: $1773-1780$

2. Moses JW, Leon MB, Popma JJ, Fitzgerald PJ, Holmes DR, O'Shaughnessy C, et al. Sirolimus-eluting stents versus standard stents in patients with stenosis in a native coronary artery. $N$ Engl $J$ Med 2003; 349: 1315-1323.

3. Holmes DR Jr, Leon MB, Moses JW, Popma JJ, Cutlip D, Fitzgerald $\mathrm{PJ}$, et al. Analysis of 1-year clinical outcomes in the SIRIUS trial: A randomized trial of a sirolimus-eluting stent versus a standard stent in patients at high risk for coronary restenosis. Circulation 2004; 109: $634-640$.

4. Schofer J, Schluter M, Gershlick AH, Wijns W, Garcia E, Schampaert $\mathrm{E}$, et al. Sirolimus-eluting stents for treatment of patients with long atherosclerotic lesions in small coronary arteries: Double-blind, randomised controlled trial (E-SIRIUS). Lancet 2003; 362: 1093-1099.

5. Schampaert E, Cohen EA, Schluter M, Reeves F, Traboulsi M, Title LM, et al. The Canadian study of the sirolimus-eluting stent in the treatment of patients with long de novo lesions in small native coronary arteries (C-SIRIUS). J Am Coll Cardiol 2004; 43: 1110-1115.

6. Schampaert E, Moses JW, Schofer J, Schluter M, Gershlick AH, Cohen EA, et al. Sirolimus-eluting stents at two years: A pooled analysis of SIRIUS, E-SIRIUS, and C-SIRIUS with emphasis on late revascularizations and stent thromboses. Am J Cardiol 2006; 98: $36-41$.

7. Urban P, Gershlick AH, Guagliumi G, Guyon P, Lotan C, Schofer J, et al. Safety of coronary sirolimus-eluting stents in daily clinical practice: One-year follow-up of the e-Cypher registry. Circulation 2006; 113: $1434-1441$.

8. Lemos PA, Serruys PW, van Domburg RT, Saia F, Arampatzis CA, Hoye A, et al. Unrestricted utilization of sirolimus-eluting stents compared with conventional bare stent implantation in the "real world": The Rapamycin-Eluting Stent Evaluated At Rotterdam Cardiology Hospital (RESEARCH) registry. Circulation 2004; 109: 190-195.

9. Bavry AA, Kumbhani DJ, Helton TJ, Bhatt DL. Risk of thrombosis with the use of sirolimus-eluting stents for percutaneous coronary intervention (from registry and clinical trial data). Am J Cardiol 2005; 95: 1469-1472.

10. Berger PB, Bell MR, Rihal CS, Ting H, Barsness G, Garratt K, et al. Clopidogrel versus ticlopidine after intracoronary stent placement. J Am Coll Cardiol 1999; 34: 1891-1894.

11. Bertrand ME, Rupprecht HJ, Urban P, Gershlick AH. Double-blind study of the safety of clopidogrel with and without a loading dose in combination with aspirin compared with ticlopidine in combination with aspirin after coronary stenting: The clopidogrel aspirin stent international cooperative study (CLASSICS). Circulation 2000; 102: 624-629.

12. Bhatt DL, Bertrand ME, Berger PB, L'Allier PL, Moussa I, Moses JW, et al. Meta-analysis of randomized and registry comparisons of ticlopidine with clopidogrel after stenting. J Am Coll Cardiol 2002; 39: $9-14$.

13. Muller C, Buttner HJ, Petersen J, Roskamm H. A randomized com- parison of clopidogrel and aspirin versus ticlopidine and aspirin after the placement of coronary-artery stents. Circulation 2000; 101: 590593.

14. Juergens CP, Wong AM, Leung DY, Lowe HC, Lo S, Fernandes C, et al. A randomized comparison of clopidogrel and aspirin versus ticlopidine and aspirin after coronary stent implantation. Am Heart $J$ 2004; 147: E15.

15. Grines CL, Bonow RO, Casey DE Jr, Gardner TJ, Lockhart PB, Moliterno DJ, et al. Prevention of premature discontinuation of dual antiplatelet therapy in patients with coronary artery stents: A science advisory from the American Heart Association, American College of Cardiology, Society for Cardiovascular Angiography and Interventions, American College of Surgeons, and American Dental Association, with representation from the American College of Physicians. Circulation 2007; 115: 813-818.

16. Thebault JJ, Blatrix CE, Blanchard JF, Panak EA. Effects of ticlopidine, a new platelet aggregation inhibitor in man. Clin Pharmacol Ther 1975; 18: 485-490.

17. David JL, Monfort F, Herion F, Raskinet R. Compared effects of three dose-levels of ticlopidine on platelet function in normal subjects. Thromb Res 1979; 14: 35-49.

18. Picard-Fraire C. Ticlopidine hydrochloride: Relationship between dose, kinetics, plasma concentration and effect on platelet function. Thromb Res Suppl 1983; 4: 119-128.

19. Ruan C, Destelle G, Wang Z, Wan H, He Y, Cheng D, et al. Ticlopidine in China: Comparative study on the effect of two dose levels on bleeding time and platelet function in healthy volunteers. Haemostasis 1989; 19: 94-99.

20. Fukuuchi Y, Tohgi H, Okudera T, Ikeda Y, Miyanaga Y, Uchiyama $\mathrm{S}$, et al. A randomized, double-blind study comparing the safety and efficacy of clopidogrel versus ticlopidine in Japanese patients with noncardioembolic cerebral infarction. Cerebrovasc Dis 2008; 25: $40-49$.

21. Steg PG, Bhatt DL, Wilson PW, D'Agostino R Sr, Ohman EM, Rother $\mathrm{J}$, et al. One-year cardiovascular event rates in outpatients with atherothrombosis. JAMA 2007; 297: 1197-1206.

22. Fukushima K, Kobayashi Y, Okuno T, Nakamura Y, Sakakibara M, Nakayama T, et al. Incidence of side-effects of ticlopidine after sirolimus-eluting stent implantation. Circ J 2007; 71: 617-619.

23. Iwata Y, Kobayashi Y, Fukushima K, Kitahara H, Asano T, Ishio N, et al. Incidence of premature discontinuation of antiplatelet therapy after sirolimus-eluting stent implantation. Circ J 2008; 72: 340-341.

24. Morice MC, Colombo A, Meier B, Serruys P, Tamburino C, Guagliumi G, et al. Sirolimus- vs paclitaxel-eluting stents in de novo coronary artery lesions: The REALITY trial: A randomized controlled trial. JAMA 2006; 295: 895-904.

25. Saia F, Piovaccari G, Manari A, Santarelli A, Benassi A, Aurier E, et al. Clinical outcomes for sirolimus-eluting stents and polymer-coated paclitaxel-eluting stents in daily practice: Results from a large multicenter registry. J Am Coll Cardiol 2006; 48: 1312-1318.

26. Abbott JD, Vlachos HA, Selzer F, Sharaf BL, Holper E, Glaser R, et al. Gender-based outcomes in percutaneous coronary intervention with drug-eluting stents (from the National Heart, Lung, and Blood Institute Dynamic Registry). Am J Cardiol 2007; 99: 626-631.

27. Turco MA, Ormiston JA, Popma JJ, Mandinov L, O'Shaughnessy CD, Mann T, et al. Polymer-based, paclitaxel-eluting TAXUS Liberte stent in de novo lesions: The pivotal TAXUS ATLAS trial. $J$ Am Coll Cardiol 2007; 49: 1676-1683.

28. Williams DO, Abbott JD, Kip KE. Outcomes of 6906 patients undergoing percutaneous coronary intervention in the era of drug-eluting stents: Report of the DEScover Registry. Circulation 2006; 114: $2154-2162$.

29. Abizaid A, Chan C, Lim YT, Kaul U, Sinha N, Patel T, et al. Twelvemonth outcomes with a paclitaxel-eluting stent transitioning from controlled trials to clinical practice (the WISDOM Registry). Am J Cardiol 2006; 98: 1028-1032.

30. Zahn R, Hamm CW, Schneider S, Zeymer U, Nienaber CA, Richardt $\mathrm{G}$, et al. Incidence and predictors of target vessel revascularization and clinical event rates of the sirolimus-eluting coronary stent (results from the prospective multicenter German Cypher Stent Registry). Am J Cardiol 2005; 95: 1302-1308.

31. Windecker S, Remondino A, Eberli FR, Juni P, Raber L, Wenaweser $\mathrm{P}$, et al. Sirolimus-eluting and paclitaxel-eluting stents for coronary revascularization. $N$ Engl J Med 2005; 353: 653-662.

32. Kumar S, Suresh V, Prendergast BD, Brooks NH, Wicks P, Levy RD, et al. Outcome in the real-world of coronary high-risk intervention with drug-eluting stents (ORCHID) -a single-center study comparing Cypher sirolimus-eluting with Taxus paclitaxel-eluting stents. Catheter Cardiovasc Interv 2006; 68: 663-668.

33. Takahashi S, Kaneda H, Tanaka S, Miyashita Y, Shiono T, Taketani 
Y, et al. Late angiographic stent thrombosis after sirolimus-eluting stent implantation. Circ J 2007; 71: 226-228.

34. Hur SH, Kitamura K, Morino Y, Honda Y, Jones M, Korr KS, et al. Efficacy of postdeployment balloon dilatation for current generation stents as assessed by intravascular ultrasound. Am J Cardiol 2001; 88: $1114-1119$.

35. Brodie BR, Cooper C, Jones M, Fitzgerald P, Cummins F. Is adjunctive balloon postdilatation necessary after coronary stent deployment? Final results from the POSTIT trial. Catheter Cardiovasc Interv 2003; 59: $184-192$

36. Blackman DJ, Porto I, Shirodaria C, Channon KM, Banning AP. Usefulness of high-pressure post-dilatation to optimize deployment of drug-eluting stents for the treatment of diffuse in-stent coronary restenosis. Am J Cardiol 2004; 94: 922-925.

37. Hoffmann R, Guagliumi G, Musumeci G, Reimers B, Petronio AS, Disco C, et al. Vascular response to sirolimus-eluting stents delivered with a nonaggressive implantation technique: Comparison of intravascular ultrasound results from the multicenter, randomized E-SIRIUS, and SIRIUS trials. Catheter Cardiovasc Interv 2005; 66: 499-506.

38. Fitzgerald PJ, Oshima A, Hayase M, Metz JA, Bailey SR, Baim DS, et al. Final results of the Can Routine Ultrasound Influence Stent Expansion (CRUISE) study. Circulation 2000; 102: 523-530.
39. Oemrawsingh PV, Mintz GS, Schalij MJ, Zwinderman AH, Jukema JW, van der Wall EE. Intravascular ultrasound guidance improves angiographic and clinical outcome of stent implantation for long coronary artery stenoses: Final results of a randomized comparison with angiographic guidance (TULIP Study). Circulation 2003; 107: $62-67$.

40. Sonoda S, Morino Y, Ako J, Terashima M, Hassan AH, Bonneau $\mathrm{HN}$, et al. Impact of final stent dimensions on long-term results following sirolimus-eluting stent implantation: Serial intravascular ultrasound analysis from the sirius trial. J Am Coll Cardiol 2004; 43: 1959- 1963.

41. Waseda K, Ako J, Kaneda H, Miyazawa A, Shimada Y, Morino Y, et al. Effect of lumen narrowing within sirolimus-eluting stents on proximal and distal vessel segments. Circ J 2008; 72: 534-537.

42. Rao SV, Shaw RE, Brindis RG, Klein LW, Weintraub WS, Peterson ED. On- versus off-label use of drug-eluting coronary stents in clinical practice (report from the American College of Cardiology National Cardiovascular Data Registry [NCDR]). Am J Cardiol 2006; 97: $1478-1481$.

43. Ishio N, Kobayashi Y, Takebayashi H, Iijima Y, Kanda J, Nakayama $\mathrm{T}$, et al. Impact of drug-eluting stents on clinical and angiographic outcomes in dialysis patients. Circ J 2007; 71: 1525-1529. 